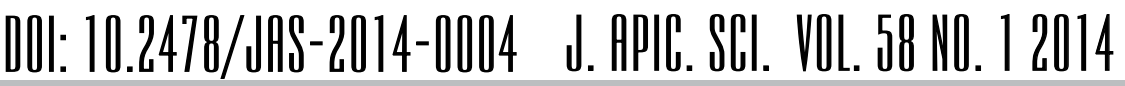

Original Article

\section{THE ANTIOXIDANT ACTIVITY OF MALTESE HONEY}

\author{
Natacha Meinen ${ }^{1}$ \\ Liberato Camilleri² \\ Everaldo Attard ${ }^{3 *}$
}

\author{
${ }^{1}$ Agrosup Dijon - 26 Bd Dr Petitjean, BP 87999 , 21079 DIJON CEDEX - France \\ 2Statistics and Operations Research, Faculty of Science, \\ University of Malta, Msida, MSD2080 Malta \\ ${ }^{3}$ Division of Rural Sciences and Food Systems, \\ Institute of Earth Systems, University of Malta, Msida, MSD2080 Malta
}

*corresponding author: everaldo.attard@um.edu.mt
Received 18 January 2013; accepted 05 February 2014

A b s t ract

Maltese honey has been valued for its medicinal properties since ancient times, so much so that the word Malta is derived from the ancient Greek word, Melite, which means honey. In this study, Maltese honey samples $(n=30)$ from three harvest seasons and different floral sources were analysed to determine their antioxidant/antiradical properties. Colorimetric assays were used to determine the polyphenol content, flavonoid content, and colour intensity, and these values were analysed to determine whether they correlated with radical scavenging activity as determined by bioassays. The honey samples varied in their DPPH activity (range, $3.326-11.865 \mathrm{mg} \mathrm{AEAC/100} \mathrm{g} \mathrm{honey),} \mathrm{reducing}$ power ( $\mathrm{EC}_{50}$ range: 5.632 - $14.453 \mathrm{mg} / \mathrm{ml}$ ), total phenolic content (range, 8.114 - 109.765 $\mathrm{mg} \mathrm{TAE} / 100 \mathrm{~g}$ honey), total flavonoids (range, 0.655 - $212.865 \mathrm{mg} \mathrm{RE} / 100 \mathrm{~g}$ honey), and colour intensity (range, 0.000 - $99.581 \mathrm{~mm}$ Pfund). The data were subjected to factor analysis using principal components. The antioxidant properties correlated significantly with total polyphenol content and colour $(p<0.0001)$. Principal components analysis revealed three clusters of honey corresponding to the three harvest seasons.

Keywords: antioxidant activity, flavonoids, Maltese honey, PCA, phenols.

\section{INTRODUCTION}

Because of its antimicrobial, anti-inflammatory, and antioxidant properties, honey is used to treat medical conditions such as burns, skin ulcers, and eye ailments like cataracts (National Honey Board, 2002). Apart from its therapeutic applications, honey has been studied in the context of the deteriorative oxidation reactions in food that are caused by light, heat, and some metals. Inhibition of food deterioration by honey has been demonstrated in studies of the enzymatic browning of fruits and vegetables, lipid oxidation in meat, and growth suppression of foodborne pathogens and food spoilage organisms (Chen et al., 2000; Mundo et al., 2004; Nagai et al., 2006; Ferreira et al., 2009).

The antioxidants in honey are categorized as enzymatic (e.g. catalase, glucose oxidase, and peroxidase) and non-enzymatic (National Honey Board, 2002). The latter category includes a wide array of metabolites, such as ascorbic acid, $\alpha$-tocopherols, carotenoids, amino acids, proteins, organic acids, Maillard reaction products, and more than 150 polyphenolic compounds such as flavonoids, phenolic acids, tannins, and their derivatives (Ferreira et al., 2009). Moreover, the physicochemical and biological characteristics of honey can be affected by the floral sources and by environmental and seasonal factors. Notably, dark honey and honey with high moisture levels have higher antioxidant activities. The antioxidant activity of honey correlates with potential alkalinity, ash content, and with antioxidant pigments such as carotenoids and flavonoids (Sangsrichan and Wanson, 2008).

In Malta, dark coloured carob honey is traditionally used to treat coughs and colds. In some cases, carob syrup is used as a substitute for carob honey. Thyme honey, a typical summer honey, is also used to treat coughs and colds, mainly by dissolving a teaspoonful of honey in a 150-mL cup of hot water 
and adding a few drops of lemon juice to supplement the astringent and antioxidant properties of honey (Lanfranco, 2001).

In this study, we aimed to determine the antioxidant activity of Maltese honey and to investigate whether this activity was related to a particular phytochemical class or to a particular season.

\section{MATERIAL AND METHODS}

Honey samples produced by Apis mellifera ruttneri (Sheppard et al., 1997) were collected in different regions of Malta in three seasons: autumn 2011 (AU 2011; September to December; carob/ eucalyptus), spring 2012 (SP 2102; March to June; mixed flora), and summer 2012 (SU 2012; July and August; wild thyme). Random samples that were representative of each season were collected following physicochemical characterization of the different honey types (Bugeja Douglas and Attard, 2012). The samples were stored at $4^{\circ} \mathrm{C}$ until further analysis. A $50 \%(\mathrm{w} / \mathrm{v})$ solution was prepared from each honey sample and then centrifuged at $1500 \mathrm{x}$ $\mathrm{g}$ for $5 \mathrm{~min}$. The supernatant was used as the stock solution.

Antiradical activity determination: the DPPH assay

The DPPH assay (2,2-diphenyl-1-picrylhydrazyl, Sigma Aldrich, USA) was modified for the honey matrix (Moein et al., 2007). Briefly, each honey sample was prepared as a $12.5 \%(\mathrm{w} / \mathrm{v})$ solution in distilled water, and $200 \mu \mathrm{L}$ of a $100 \mu \mathrm{M}$ solution of DPPH radical in methanol were added to $20 \mu \mathrm{L}$ of each sample in micro-plate wells (Nunc, Denmark). After mixing, the reactions were incubated for $30 \mathrm{~min}$ at room temperature in the dark. DPPH radical inhibition was measured at $490 \mathrm{~nm}$ against reference mixtures in which the DPPH solution was replaced with methanol. Ascorbic acid (BDH, UK) was used as a standard (10 - $100 \mu \mathrm{g} / \mathrm{mL})$. The AAE-DPPH (Ascorbic Acid Equilavalents against the DPPH Assay) and ascorbic acid equivalence (mg AEAC/100 $g$ honey) $\left(r^{2}=0.9928\right)$ were calculated.

\section{Honey colour}

Honey colour was determined by measuring the absorbance of $50 \%$ honey solutions (w/v) at $630 \mathrm{~nm}$ using a microplate reader. The honey samples were classified according to the Pfund scale after conversion of the absorbance (Abs) values to mmPfund according to the formula: mmPfund $=-38.70+371.39 \times$ Abs (Kaškoniene et al., 2009)

\section{Phenolic compounds}

The total phenolic content (TP) was determined using Folin Ciocalteu's reagent (Attard, 2013). Briefly, $100 \mu \mathrm{L}$ of Folin-Ciocalteu reagent (Sigma-Aldrich, pre-diluted 1:9 with distilled water and $80 \mu \mathrm{L}$ of sodium carbonate $\left(\mathrm{Na}_{2} \mathrm{CO}_{3}\right.$; SigmaAldrich, $1 \mathrm{M}$ ) were added to $10 \mu \mathrm{L}$ of each honey stock solution. The absorbance was measured at $630 \mathrm{~nm}$ after incubation for $20 \mathrm{~min}$ at room temperature using a microplate reader (BioTek ELx800, Winooski, VT, USA). Tannic acid (Sigma-Aldrich) was used as a standard $\left(60-960 \mathrm{mg} / \mathrm{mL} ; r^{2}=0.9941\right)$ to prepare a calibration curve in order to determine the total amount of phenols in each honey sample (mg TAE/100 g of honey).

\section{Total flavonoid content}

The total flavonoid (TF) content of honey samples was determined using a colorimetric method (Moein et al., 2007; Moein and Reza Moein, 2010). Briefly, $25 \mu \mathrm{L}$ aliquots of $50 \%(\mathrm{w} / \mathrm{v})$ honey samples were mixed with $100 \mu \mathrm{L}$ of $0.15 \% \quad \mathrm{NaNO}_{2}$ solution (Fisher Scientific, UK). After $6 \mathrm{~min}, 100 \mu \mathrm{L}$ of $4 \%$ $\mathrm{NaOH}$ solution was added to the mixture, followed by $25 \mu \mathrm{L}$ of distilled water, for a final volume of $250 \mu \mathrm{L}$. After resting for $15 \mathrm{~min}$, the absorbance of the mixture was determined at $510 \mathrm{~nm}$ using water as a blank. Rutin (Sigma-Aldrich, USA) was used as a standard for the quantification of total flavonoid content $\left(0-500 \mathrm{mg} / \mathrm{mL} ; r^{2}=0.9962\right)$.

\section{Reducing Power}

The reducing power or FRAP (Ferric Reducing Antioxidant Power) of honey samples was determined using the method of Oyaizu (1986). Honey solutions $(50 \%, 25 \%, 12.5 \%$ and $6.25 \%(w / v))$ in $250 \mu \mathrm{L}$ of distilled water or $250 \mu \mathrm{L}$ of distilled water (blank) were mixed with $250 \mu \mathrm{L}$ of $0.2 \mathrm{M}$ phosphate buffer (pH 6.6) and $250 \mu \mathrm{L}$ of $1 \%$ potassium ferricyanide (Sigma-Aldrich, USA). The mixture was incubated at $50^{\circ} \mathrm{C}$ for $20 \mathrm{~min}$ and then rapidly cooled in an ice bath for $30 \mathrm{~s}$. Following this, $250 \mu \mathrm{L}$ of $10 \%$ trichloroacetic acid (TCA, Fisher Scientific, UK) were added and the mixture was centrifuged at $3000 \mathrm{rpm}$ for $10 \mathrm{~min}$. Next, $500 \mu \mathrm{L}$ of the upper layer were mixed with $500 \mu \mathrm{L}$ of distilled water plus $100 \mu \mathrm{L}$ of $0.1 \%$ ferric chloride (Acros Organics, UK). The absorbance of these mixtures was measured at $700 \mathrm{~nm}$ against a blank (Mohamed et al., 2012). The $\mathrm{EC}_{50}$ was used to define the specific reducing capability (mg AEAC/100 g honey) using ascorbic acid $\left(10-100 \mu \mathrm{g} / \mathrm{ml} ; r^{2}=0.9981\right)$ as a positive control. 


\section{Data analysis}

All measurements were performed in triplicate. The $\mathrm{EC}_{50}$ values were determined using Statplus 2009 5.8.4.0 (Analystsoft, USA). All statistical analyses of the variables AAE-DPPH, colour, TP, TF, TFI TP, EC50-RedPw (Median Effective Concentration for the Reducing Power Assay), and AAE-RedPw (Asorbic Acid Equivalents according to the Reducing Power Assay) were performed using SPSS (IBM version 22). The Kolmogorov-Smirnov test revealed that the variable values had fairly normal distributions and so the one-way ANOVA test was used to compare the mean variable values in the three seasons (AU 2011, SP 2012, and SU 2012). The null hypothesis specifies that the mean variable values are comparable in the three seasons and is accepted if the p-value exceeds the 0.05 level of significance. The alternative hypothesis specifies that mean variable values differ significantly in the three seasons and is accepted if the p-value is less than the 0.05 criterion. The Dunnett T3 post-hoc test was used for pairwise comparison since the Levene's test revealed that the variances of the variable values differed significantly in the three seasons.

Considering that the variable values have metric scales and normal distributions, Pearson correlation, which ranges from -1 to 1 , was used pairwise to measure the strength of the relationship between the variables. The null hypothesis specifies that the two variables are unrelated (Pearson correlation is close to 0 ) and is accepted if the p-value exceeds the 0.05 level of significance. The alternative hypothesis specifies that the two variables are significantly related (Pearson correlation is significantly different from 0 ) and is accepted if the p-value is less than the 0.05 criterion.

Factor analysis using principal components was used to identify latent traits within the data. The KaiserMeyer-Olkin (KMO) measure was used to determine whether latent trends exist within the data, and Bartlett's test of sphericity was used to determine if the variables were related and therefore suitable for structure detection.

\section{RESULTS}

Results of the chemical and biological analysis of the Maltese honey samples are shown in Table 1, which reports the mean variable values for all 30 honey samples and the $95 \%$ confidence limits of the actual mean variable values for each season. Honey colour ranged from water white $(0.00 \mathrm{~mm}$ Pfund) to amber (111.84 mm Pfund). Both the One-Way ANOVA and the Dunnett T3 post hoc test revealed that the mean colour of SP 2012 honey (18.163 $\pm 6.911 \mathrm{mmPfund})$ was significantly lower than that of honey from the other two seasons (AU 2011: $57.899 \pm 14.112$ and SU 2012: $47.722 \pm 9.228 \mathrm{~mm}$ Pfund). The phenolic compounds ranged from 28.11 to $109.777 \mathrm{mg}$ TAE/100 g honey. The three darker honey samples collected during autumn had higher amounts of phenolic compounds: AU01, AU02, and AU05 had 104.97, 109.77, and 103.83 mg TAE/100 g honey, respectively. One-Way ANOVA showed that the mean phenolic levels were considerably higher in the autumn samples than in the spring and summer samples, while the Dunnett T3 post hoc test revealed that the mean TP mg TAE/100 g honey in SP 2012 (56.943 \pm 7.027$)$ was significantly lower than in the other two seasons (AU 2011: $79.692 \pm$ 8.000 and SU 2012: $69.598 \pm 3.208 \mathrm{mg}$ TAE/100 g honey). The flavonoid content in the Maltese honey ranged from 2.00 to $81.16 \mathrm{mg}$ RE/100 g honey. In three instances, the values were out of this range; for honey sample SU09, the flavonoid level was undetectable, while for samples AUO3 and AU07, the flavonoid levels were extremely high (212.86 and $197.57 \mathrm{mg} R E / 100 \mathrm{~g}$ honey, respectively). In fact, after removing the outliers from the data set, there was no statistical difference in the flavonoid content of the autumn, spring, and summer honey samples, which had $31.154 \pm 17.729,37.651 \pm 8.460$, and $31.420 \pm 11.373 \mathrm{mg}$ RE/100 g honey, respectively. The anti-oxidant activity of Maltese honey was analysed using bench top bioassays. In this study, the reducing power values ranged from 3.31 to $10.66 \mathrm{mg}$ AEAC/100 g honey. The One-Way ANOVA and the Dunnett T3 post hoc tests confirmed that the mean AAE-RedPw mg AEAC/100 g honey for SP 2012 (5.980 \pm 0.653$)$ was significantly lower than for the other two seasons (AU 2011: $7.54 \pm$ 0.798 and SU 2012: $6.96 \pm 0.242 \mathrm{mg} \mathrm{AEAC/100} \mathrm{g}$ honey). Likewise, the value for $50 \%$ inhibition of oxidation ranged from 7.39 to $28.26 \mathrm{mg} / \mathrm{ml}$. Both the One-Way ANOVA and the Dunnett T3 post hoc test revealed that the mean AAE-RedPw mg AEAC/100 g honey in AU 2011 (12.67 $\pm 1.093 \mathrm{mg}$ AEAC/100 g) was significantly lower than in SU 2012 (14.250 \pm $0.035 \mathrm{mg}$ AEAC/100 g), which in turn was significantly lower than in SP 2012 (16.600 $\pm 1.979 \mathrm{mg}$ AEAC/100 g). The Maltese honey samples had antiradical activity values between 3.33 and $15.62 \mathrm{mg}$ AEAC/100 g honey. The One-Way ANOVA test revealed that the mean AAE-DPPH mg AEAC/100 g honey in AU 2011 (9.300 \pm 1.292$)$ was considerably higher than in SP 2012 (5.805 \pm 0.610$)$ and 
Table 1.

Chemical and antioxidant analysis of Maltese honey from three harvest seasons ${ }^{a}$

\begin{tabular}{|c|c|c|c|c|c|c|c|}
\hline $\begin{array}{l}\text { Honey } \\
\text { samples }\end{array}$ & $\begin{array}{c}\text { AAE-DPPH } \\
\text { mg AEAC/100 } \\
\text { g honey }\end{array}$ & $\begin{array}{l}\text { Colour } \\
\text { mmPfund }\end{array}$ & $\begin{array}{c}\text { TP } \\
\text { mg TAE/100 } \\
\text { g honey } \\
\end{array}$ & $\begin{array}{c}\text { TF } \\
\mathrm{mg} \text { RE/100 g } \\
\text { honey }\end{array}$ & TF/TP & $\begin{array}{c}\text { AAE-RedPw } \\
\text { mg AEAC/100 } \\
\text { g honey }\end{array}$ & $\begin{array}{l}\text { EC50-RedPw } \\
\mathrm{mg} \text { honey/mL }\end{array}$ \\
\hline AU01 & 9.79 & 111.84 & 104.97 & 7.98 & 0.074 & 10.36 & 7.39 \\
\hline AU02 & 15.62 & 109.48 & 109.77 & 13.75 & 0.127 & 10.66 & 7.53 \\
\hline AU03 & 5.68 & 33.23 & 64.02 & $212.86^{c}$ & $3.337^{c}$ & 6.39 & 14.33 \\
\hline AU04 & 4.06 & 3.51 & 56.43 & 56.54 & 1.002 & 4.69 & 14.44 \\
\hline AU05 & 9.76 & 90.79 & 103.83 & 9.31 & 0.088 & 9.76 & 11.81 \\
\hline AU06 & 11.86 & 74.57 & 93.89 & 25.94 & 0.282 & 8.41 & 14.07 \\
\hline AU07 & 10.59 & 44.00 & 77.03 & $197.57^{c}$ & $2.565^{c}$ & 7.54 & 14.21 \\
\hline AU08 & 8.61 & 49.07 & 74.02 & 67.85 & 0.916 & 6.78 & 14.27 \\
\hline AU09 & 10.65 & 59.22 & 57.16 & 54.55 & 0.951 & 5.85 & 14.32 \\
\hline AU10 & 6.35 & 3.27 & 55.80 & 13.30 & 0.244 & 4.98 & 14.39 \\
\hline $\begin{array}{c}\text { Autumn } \\
2011^{\mathrm{b}} \\
\end{array}$ & $\begin{array}{l}9.30 \pm \\
1.292 \\
\end{array}$ & $\begin{array}{c}57.899 \pm \\
14.11 \\
\end{array}$ & $\begin{array}{c}79.692 \pm \\
8.00\end{array}$ & $\begin{array}{c}31.15 \pm \\
17.73 \\
\end{array}$ & $\begin{array}{l}0.46 \pm \\
0.303\end{array}$ & $\begin{array}{l}7.54 \pm \\
0.798 \\
\end{array}$ & $\begin{array}{c}12.67 \pm \\
1.093 \\
\end{array}$ \\
\hline SP01 & 4.15 & 2.77 & 32.62 & 19.29 & 0.593 & 4.08 & 23.64 \\
\hline SP02 & 5.62 & 29.02 & 74.02 & 39.25 & 0.529 & 7.01 & 14.19 \\
\hline SP03 & 3.77 & 12.92 & 51.73 & 33.93 & 0.662 & 5.47 & 14.40 \\
\hline SP04 & 6.93 & 16.14 & 45.35 & 17.30 & 0.384 & 4.96 & 14.42 \\
\hline SP05 & 6.45 & 5.25 & 59.07 & 57.87 & 0.981 & 7.86 & 14.15 \\
\hline SP06 & 7.79 & 19.98 & 65.57 & 59.20 & 0.902 & 6.19 & 14.31 \\
\hline SP07 & 6.64 & 35.08 & 54.84 & 9.98 & 0.184 & 6.34 & 14.35 \\
\hline SP08 & 8.04 & 60.46 & 93.61 & 71.18 & 0.756 & 9.43 & 13.89 \\
\hline SP09 & 4.41 & 0.00 & 28.11 & 18.63 & 0.692 & 3.31 & 28.26 \\
\hline SP10 & 4.25 & 0.00 & 64.50 & 49.89 & 0.765 & 5.14 & 14.41 \\
\hline $\begin{array}{l}\text { Spring } \\
2012^{b}\end{array}$ & $\begin{array}{c}5.805 \pm \\
0.610\end{array}$ & $\begin{array}{c}18.163 \pm \\
6.911 \\
\end{array}$ & $\begin{array}{c}56.943 \pm \\
7.027\end{array}$ & $\begin{array}{c}37.651 \pm \\
8.460 \\
\end{array}$ & $\begin{array}{c}0.642 \pm \\
0.154 \\
\end{array}$ & $\begin{array}{c}5.980 \pm \\
0.653\end{array}$ & $\begin{array}{c}16.60 \pm \\
1.979 \\
\end{array}$ \\
\hline SU01 & 6.80 & 48.70 & 76.91 & 71.84 & 0.931 & 7.15 & 14.27 \\
\hline SU02 & 5.49 & 88.93 & 75.51 & 2.44 & 0.032 & 7.18 & 14.21 \\
\hline SU03 & 6.26 & 51.67 & 64.91 & 25.94 & 0.419 & 6.83 & 14.35 \\
\hline SU04 & 6.51 & 57.86 & 74.56 & 42.57 & 0.582 & 7.02 & 14.25 \\
\hline SU05 & 5.40 & 75.69 & 79.13 & 11.75 & 0.149 & 8.09 & 14.15 \\
\hline SU06 & 4.51 & 16.64 & 65.29 & 20.62 & 0.317 & 6.57 & 14.28 \\
\hline SU07 & 5.75 & 22.08 & 70.15 & 2.00 & 0.028 & 5.71 & 14.41 \\
\hline SU08 & 3.80 & 40.65 & 72.43 & 81.16 & 1.120 & 7.36 & 14.16 \\
\hline SU09 & 4.54 & 63.56 & 63.26 & 0.00 & 0.000 & 7.25 & 14.18 \\
\hline SU10 & 3.33 & 11.44 & 53.80 & 55.88 & 1.019 & 6.40 & 14.29 \\
\hline $\begin{array}{c}\text { Summer } \\
2012^{\mathrm{b}}\end{array}$ & $\begin{array}{c}5.238 \pm \\
0.657\end{array}$ & $\begin{array}{c}47.722 \pm \\
9.228 \\
\end{array}$ & $\begin{array}{c}69.598 \pm \\
3.208 \\
\end{array}$ & $\begin{array}{l}31.42 \pm \\
11.373 \\
\end{array}$ & $\begin{array}{c}0.460 \pm \\
0.282 \\
\end{array}$ & $\begin{array}{l}6.96 \pm \\
0.242 \\
\end{array}$ & $\begin{array}{c}14.250 \pm \\
0.035 \\
\end{array}$ \\
\hline
\end{tabular}

${ }^{a}$ Values for individual honey samples are the means of triplicate determinations.

${ }^{\mathrm{b}}$ Average values are the mean $\pm \mathrm{t} \times$ Standard Deviation, where $\mathrm{t}$ is a value that depends on the degree of confidence and the sample size.

'Data omitted for statistical purposes.

AAE-DPPH - Ascorbic Acid Equilavalents against the DPPH Assay; TP - Total Phenolic Content; TF - Total Flavonoid Content; AAE-RedPw - Asorbic Acid Equivalents according to the Reducing Power Assay; EC50-RedPw - Median Effective Concentration for the Reducing Power Assay; AEAC - Ascorbic Acid Equilavalents; TAE - Tannic Acid Equivalents; RE - Rutin Equivalents. 
Table 2.

Pearson correlation matrix for the studied parameters

\begin{tabular}{|c|c|c|c|c|c|c|}
\hline & & AAE-DPPH* & TP & Colour & $\mathrm{TF}$ & AAE-RedPw \\
\hline \multirow{2}{*}{ AAE-DPPH* } & Correlation & & & & & \\
\hline & P-value & & & & & \\
\hline \multirow{2}{*}{ TP } & Correlation & 0.605 & & & & \\
\hline & P-value & 0.000 & & & & \\
\hline \multirow{2}{*}{ Colour } & Correlation & 0.622 & 0.808 & & & \\
\hline & P-value & 0.000 & 0.000 & & & \\
\hline \multirow{2}{*}{ TF } & Correlation & 0.062 & 0.008 & -0.147 & & \\
\hline & P-value & 0.563 & 0.937 & 0.166 & & \\
\hline \multirow{2}{*}{ AAE-RedPw } & Correlation & 0.597 & 0.894 & 0.830 & -0.001 & \\
\hline & $\mathrm{P}$-value & 0.000 & 0.000 & 0.000 & 0.996 & \\
\hline \multirow{2}{*}{ EC50-RedPw } & Correlation & -0.436 & -0.703 & -0.554 & -0.022 & -0.696 \\
\hline & P-value & 0.000 & 0.000 & 0.000 & 0.836 & 0.000 \\
\hline
\end{tabular}

Values in bold are the significant Pearson correlation coefficients $(p<0.05)$.

* All abbreviations explained under Table 1.

Table 3.

Eigenvalues and variances for the six factors (principal components analysis)

\begin{tabular}{cccc}
\hline \multirow{2}{*}{ Factors } & \multicolumn{3}{c}{ Initial Eigenvalue } \\
\cline { 2 - 4 } & Eigenvalue & \% of variance & Cumulative $\%$ \\
\hline 1 & 3.729 & 62.153 & 62.153 \\
\hline 2 & 1.035 & 17.246 & 79.400 \\
\hline 3 & 0.588 & 9.806 & 89.205 \\
\hline 4 & 0.385 & 6.419 & 95.624 \\
\hline 5 & 0.159 & 2.655 & 98.279 \\
\hline 6 & 0.103 & 1.721 & 100.000 \\
\hline
\end{tabular}

SU 2012 (5.238 \pm 0.657$)$. In fact, the Dunnett T3 post hoc test showed that the value for the autumn samples was significantly higher value than for the other two seasons $(p<0.05)$.

Pearson correlation revealed that total flavonoid content was unrelated to all of the other variables (Tab. 2). AAE-DPPH, total polyphenols, colour, and AAE-RedPw were significantly positively related to each other, while EC50-RedPw was significantIy negatively related to these variables $(p<0.05)$. The data were then subjected to factor analysis using principal components. The KMO value, 0.840 , exceeded the 0.5 threshold value, indicating that factor analysis was useful for identifying latent trends in the data. The p-value of the Bartlett's test of sphericity, which was approximately 0 , was less than 0.05 , indicating that some of the variables were related and therefore suitable for structure detection. Two latent factors had an eigenvalue
Table 4.

Factor loadings for the two latent factors
\begin{tabular}{ccc} 
& \multicolumn{2}{c}{ Component } \\
\cline { 2 - 3 } & 1 & 2 \\
\hline AAE-DPPH $^{*}$ & 0.742 & 0.123 \\
\hline TP & 0.939 & 0.023 \\
\hline Colour & 0.894 & -0.171 \\
\hline TF & -0.022 & 0.992 \\
\hline AAE-RedPw & 0.941 & 0.008 \\
\hline EC50-RedPw & -0.782 & -0.070 \\
\hline All abbreviations explained under Table 1
\end{tabular}

greater than 1, which together explained $79.4 \%$ of the total variance (Tab. 3). The factor loadings of these two dominant factors are shown in Table 4. For the first factor, the factor loadings of AAE-DPPH, $\mathrm{TP}$, colour, and AAE-RedPw, which were positive; in contrast, the factor loading of EC50-RedPw was negative. The second factor weighed heavily only on total flavonoid content, which suggested that the total flavonoid level was unrelated to the other variables and is a 1 -variable factor. The factor loadings plot (Fig. 1a) shows three groups of variables. The first cluster includes TP, colour, AAE-DPPH, and AAE-RedPw; the second cluster includes only TF, and the third cluster includes only EC50-RedPw.

Figure 1b shows the factor scores of the two latent factors. Factor 1 , on the horizontal axis, contrasts EC50-RedPw with AAE-DPPH, TP, colour, and $A A E-R e d P w$ and shows that most of the observa- 
a

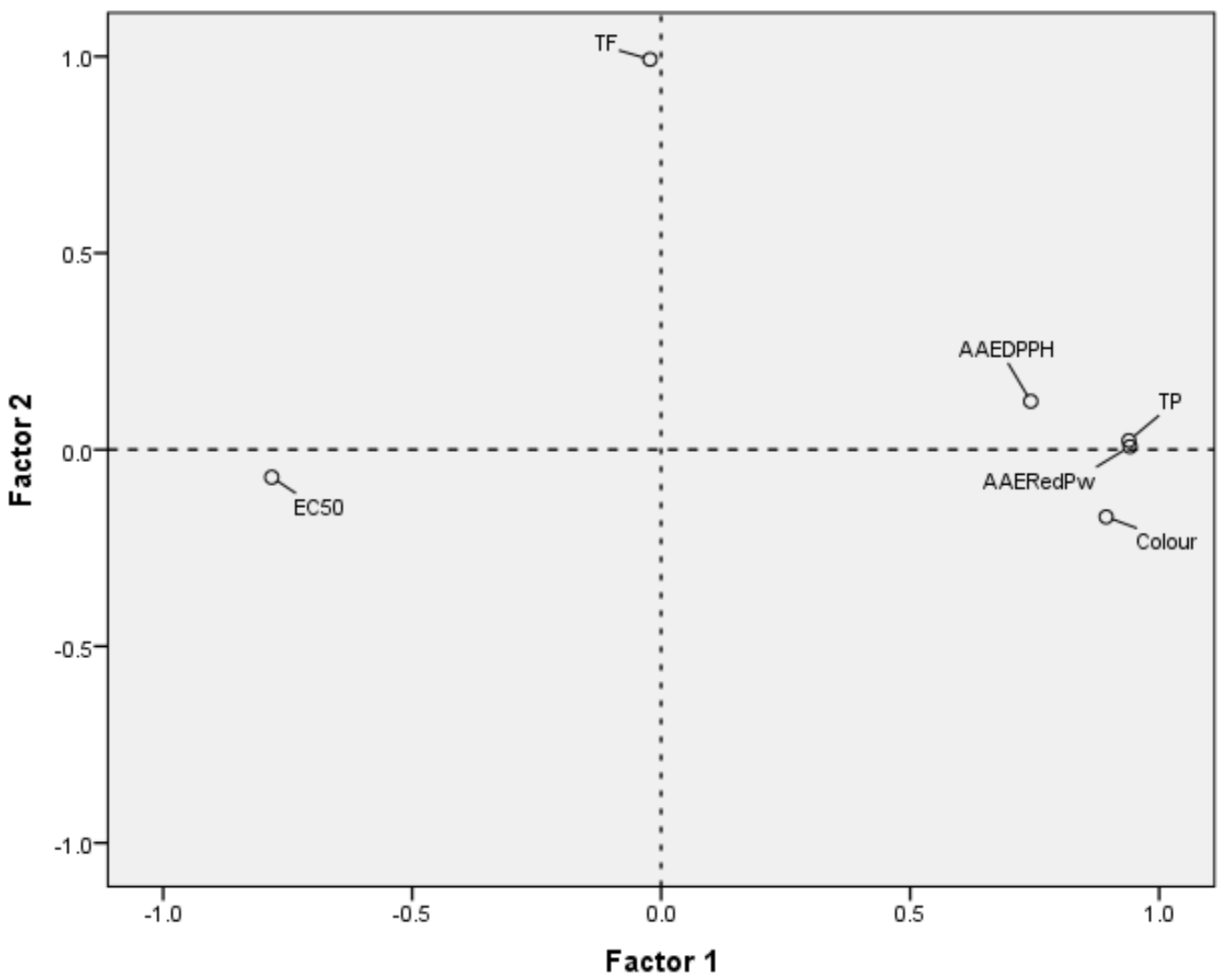

b

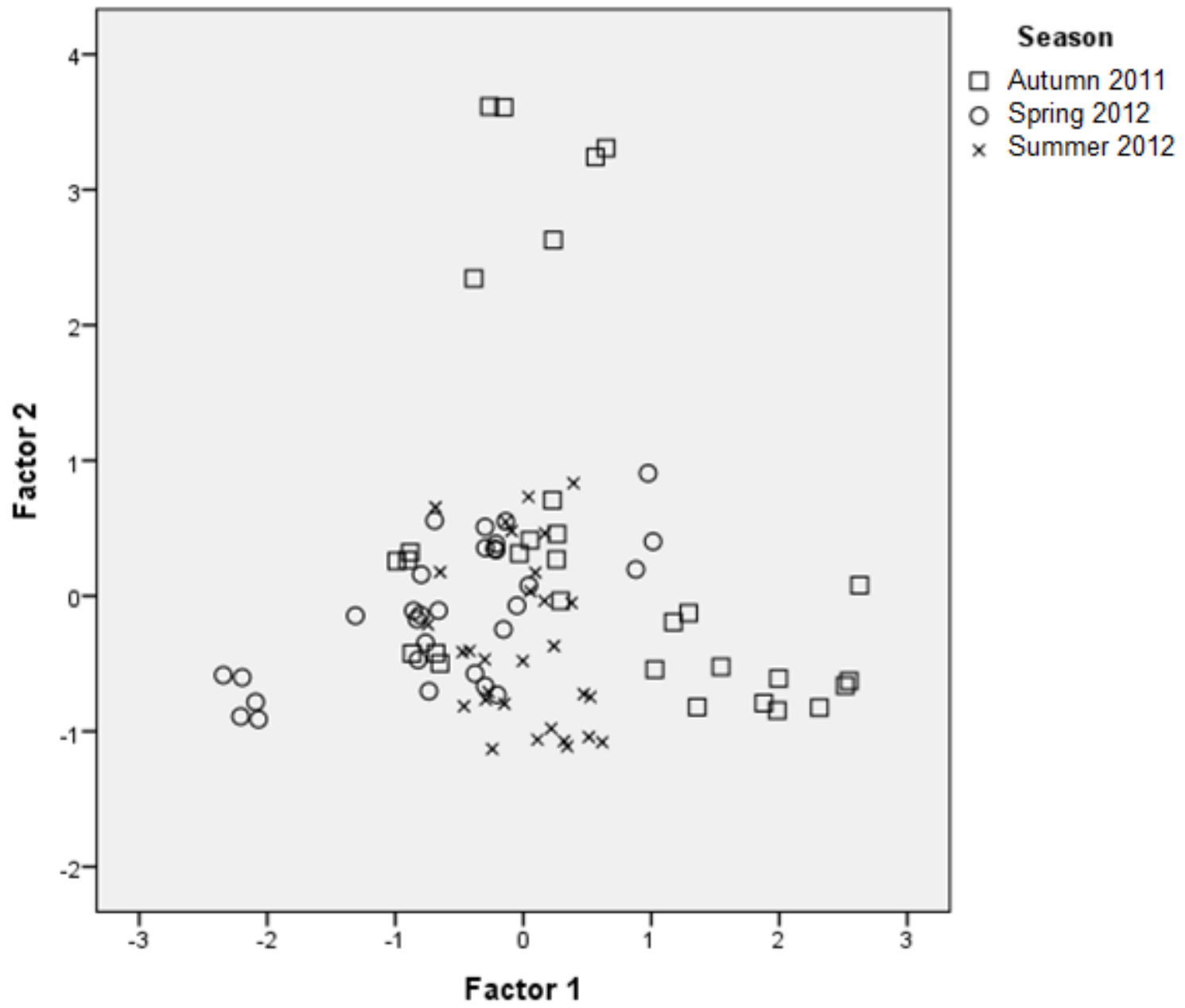

Fig. 1. (a) Factor loadings plot for the chemical and biological analyses of 30 honey samples.

(b) Factor scores plot for the investigated honey samples.

All abbreviations explained under Table 1. 


\section{J. APIC. SCL. VOL. 58 NOV. 12014}

tions on the left side of the scatter plot were from SP 2012 while most of the observations on the right side of the plot were recorded in AU 2011. This implies that the AAE-DPPH, TP, colour, and AAE-RedPw values were higher in AU 2011 and lower in SP 2012, whereas the EC50-RedPw values were higher in SP 2012 and lower in AU 2011.

\section{DISCUSSION}

This study found that honey colour was related to the floral origin of the honey. Persano Oddo and Piro (2004) reported that clover and sage honey is water white, while honeydew, heather, and chestnut honey is dark amber. Honey colour depends on its botanical origin, minerals, and other minor components, and darker honey has better radical scavenging activity due mainly to its phenolic content (Savatović et al., 2011). In the present study, there was a correlation between honey colour and antioxidant activity $(p<0.0001)$. This relationship might indicate that the presence of pigment is a reliable index of antioxidant activity. Impure honey may be contaminated by pigments during handling, processing, and storage. Colour changes may be also observed during maturation due to biochemical reactions that could lead to components without antioxidant activity (Beretta et al., 2005).

Because polyphenols have antioxidant activity, the Folin-Ciocalteu method was used to determine the total phenolic content. However, non-phenolic reducing compounds may interfere with this test, leading to an over-estimation of the phenolic content. Substances like ascorbic acid, $\alpha$-tocopherol, carotenoids, several sugars (e.g. glucose, fructose) and amino acids (e.g. histidine, taurine, glycine, and alanine) are usually cited as interfering substances. Some studies have demonstrated that the correlation between radical scavenging activity and proline is higher than that between radical scavenging activity and total phenol content (Ferreira et al., 2009; Savatović et al., 2011). We observed a weak but positive correlation between radical scavenging activity and proline content (data not shown) for local honey samples. However, further studies are needed to identify and quantify the biologically active components present in honey.

Flavonoids are low molecular weight phenolic compounds that contribute to the aroma and antioxidant properties of honey. The flavonoid content obtained in this study was higher than that obtained in similar studies. In other studies, flavonoids were present in quantities ranging from 1.35 to $9.78 \mathrm{mg}$
RE/100 g honey. Nevertheless, the type of honey investigated in these studies (Kaškoniene et al., 2009; Savatović et al., 2011) was not the same as in the present study. The ratio of the total content of phenolic compounds to flavonoids was calculated in order to evaluate the relative amounts of flavonoid and non-flavonoid compounds in honey. The seasonal average ratios ranged from 0.460 to 0.642 . This is in accordance with the ratios obtained in a study by Kaškoniene et al. (2009) in which ratios ranged between 0.05 and 0.5 , depending on the floral source of the honey.

In this study, the reducing power values were lower than those obtained by Meda et al. (2005) but compare well with those of Savatović et al. (2011). Meda et al. (2005) showed that the reducing power values of 18 multifloral honeys varied from 10.20 to $37.87 \mathrm{mg} A E A C / 100 \mathrm{~g}$ honey. In the study by Savatović et al. (2011), the reducing powers of Acacia honey, Linden honey, and "Homoljski med" (a mix of Acacia and Meadowflower) honey were $1.43,7.82$, and $4.29 \mathrm{mg} A E A C / 100 \mathrm{~g}$ honey, respectively. Higher values were reported in studies of unifloral honeys, and ranged from 13.26 to 100.80 $\mathrm{mg} / \mathrm{ml}$ (Ferreira et al., 2009; Savatović et al., 2011). In our study, the monofloral honey types, namely the autumn and summer samples, exhibited higher reducing power values (7.54 and $6.96 \mathrm{mg}$ AEAC/100 $g$ honey) than the multifloral spring samples (5.98 mg AEAC/100 g honey). Radical scavenging activity as measured with DPPH showed a trend that was similar to that of the reducing power values, except for the summer samples, which had lower values (5.238 $\pm 0.657 \mathrm{mg} A E A C / 100 \mathrm{~g}$ honey) than the spring samples (5.805 $\pm 0.610 \mathrm{mg} A E A C / 100 \mathrm{~g}$ honey). The autumn honey samples had the highest values (9.30 $\pm 1.292 \mathrm{mg} A E A C / 100 \mathrm{~g}$ honey). Due to the presence of carob nectar, the autumn honey is particularly high in polyphenols and tannins, as noted by Avallone et al. (1997).

The different parameters were analysed using principal components analysis. The fact that AAE-DPPH, TP, colour, and AAE-RedPw correlated negatively with EC50-RedPw (correlation coefficients between -0.022 and -0.703) suggests that samples with high AAE-DPPH, TP, colour, and AAE-RedPw values tend to have low EC50-RedPw values and vice versa. The total flavonoid content was an independent variable within this phytochemical-antioxidant relationship, supporting the notion that colour and polyphenol content contribute to the antioxidant activity of honey. This complements the Pearson correlations findings (Tab. 2). Principal 
components analysis showed seasonal variations (Fig. 1b). EC50-RedPw values were high in SP 2012 and low in AU 2011, whereas AAE-DPPH, TP, colour, and AAE-RedPw values were high in AU 2011 and low in SP 2012. As a result, moving from left to right in the graph, samples were categorized from low-antioxidant/light-coloured honey to high-antioxidant/ dark-coloured honey. Consequently, this reflects an anti-oxidant-based categorization of honey samples according to season as follows: spring < summer $<$ autumn. The floral sources, determined by the seasonal factor, thus contributed to the antioxidant activity of the honey. Factor 2 , displayed on the vertical axis, weighed heavily on TF. All of the values near the top of the scatter plot were recorded in AU 2011. This implies that the largest TF values were all recorded in the autumn season.

There were positive correlations between colour and total polyphenols ( $\left.r_{\text {colour } / \mathrm{TP}}=0.808\right), \mathrm{AAE}-\mathrm{DPPH}$ $\left(r_{\text {colour } / \text { AAE-DPPH }}=0.622\right)$, and AAE-RedPw $\left(r_{\text {colour/AAE-RedPw }}\right.$ $=0.830)$, and a negative correlation between $\mathrm{EC}_{50}-\operatorname{RedPw}\left(r_{\text {colour/EC50-RedPw }}=-0.554\right)$. All of these correlations were statistically significant $(p<0.05)$. There was no correlation between colour and total flavonoids in this study $\left(r_{\text {colour } / \mathrm{TF}}=-0.147, p>0.1\right)$, in contrast to the study by Khalil and et al. (2012) which found a strong interdependence between these two variables $(r=0.968)$. These results show that colour can reflect, at least in part, the antioxidant activity of a honey sample, in agreement with the conclusions of Beretta and et al. (2005) and Piljac-Žegarac and et al. (2009). In the current study, it seemed that the flavonoids were mainly flavonolbased, as these do not absorb in the $500-700 \mathrm{~nm}$ range (Tungjai et al., 2008). It is possible that other non-flavonoid polyphenolic constituents were also present in these honey samples.

Total phenols positively correlated with AAE-RedPw $\left(r_{\text {TP/AAE-RedPw }}=0.894\right)$ and, at the same time, negatively correlated with $\mathrm{EC}_{50}-\operatorname{RedPW}\left(r_{\text {TP/EC50-RedPW }}=-703\right)$. However, the total phenol values correlated less with AAE-DPPH $\left(r_{\text {TP/AAE-DPPH }}=0.605\right)$, which we also found for AAE-RedPW and AAE-DPPH ( $\Gamma_{\text {AAE-RedPw/AAE-DPPH }}=$ 0.597). Similarly, a correlation between phenols and DPPH was also found for Algerian honeys. However, a study by Khalil and et al. (2012) found a low correlation between phenols and reducing power using the FRAP assay. Others have reported strong correlations between the TP and FRAP assay results: $r=0.885$ (Beretta et al., 2005), $r=0.88$ (Krpan et al., 2009), and r = 0.873 (Piljac-Žegarac et al., 2009), in agreement with our findings $\left(r_{\text {TP/AAE-RedPw }}=0.894\right)$. Nevertheless, these authors found a strong corre- lation between TP and the DPPH assay and a high correlation between the two assays with $r>0.8$ compared with $r_{\text {AAE-RedPw/AAE-DPPH }}=0.597$ in this study. Thus, the studies by Beretta and et al. (2005), Krpan and et al. (2009), and Piljac-Žegarac and et al. (2009) suggest that phenols are the major components that are responsible for the reducing ability and radical scavenging properties of honey.

TP and TF were weakly correlated $\left(r_{\text {TP/TF }}=0.008\right)$. Most of the results obtained by others authors show a strongly linear correlation between these two parameters (Blasa et al., 2006; Ferreira et al., 2009; Khalil et al., 2012). A weak correlation was also found by Savatović and et al. (2011), indicating that the antioxidant activity is not due to phenolic compounds alone. Although individual phenols may have antioxidant potential, there may be synergistic or antagonistic interactions between phenolic and non-phenolic compounds. The presence of other constituents, as well as their synergistic effects, could contribute to the total antioxidant activity (Savatović et al., 2011). Other seasonal variations can be explained in several ways. For example, although the honey samples were collected within a specific season, a portion of this honey may have originated in the previous season (as for SU10). For example, a summer honey sample may also contain honey from spring and therefore will have values that are intermediate compared to the actual seasonal samples.

\section{CONCLUSION}

This is the first study to report a correlation of the anti-oxidant activity of Maltese honey with seasonal variations. This study is in accordance with the traditional perception that darker honey types are beneficial for treating coughs and colds, which takes advantage of the greater antioxidant activity of darker honey. The antioxidant activity of the honey was tied not only to the flavonoid content but also to the levels of other polyphenolic and non-phenolic substances. This suggests that autumn honey, which originates mainly from carob, has chemopreventive properties that are better than those of honey harvested during the summer and, in particular, in the spring.

\section{ACKNOWLEDGEMENTS}

This study was funded by the Malta Council for Science and Technology under the Research and Innovation Programme 2010 (project number R\&l2010-030). 


\section{Ј. APPC. SCL. VOL. 58 N NO. 12014}

\section{REFERENCES}

Attard E. (2013) A rapid microtitre plate Folin-Ciocalteu method for the assessment of polyphenols. Central European Journal of Biology 8(1): 48-53.

Avallone R., Plessi M., Baraldi M., Monzani A. (1997) Determination of Chemical Composition of Carob (Ceratonia siliqua): Protein, Fat, Carbohydrates, and Tannins. Journal of Food Composition and Analysis 10(2): 166-172.

Beretta G., Granata P., Ferrero M., Orioli M., Maffei Facino R. (2005) Standardization of antioxidant properties of honey by a combination of spectrophotometric/fluorimetric assays and chemometrics. Analytica Chimica Acta 533(2): 185-191.

Blasa M., Candiracci M., Accorsi A., Piacentini M. P., Albertini M. C., Piatti E. (2006) Raw Millefiori honey is packed full antioxidants. Food Chemistry 97:217-222.

Bugeja Douglas A., Attard E. (2012) Physicochemical Analysis of Maltese Honey: An Attempt to Determine Seasonal Variations in Honey. In: Book of Abstracts of II International Symposium on Bee Products and Annual Meeting of IHC. Bragança - Portugal. 9-12 September 2012: 132

Chen L., Mehta A., Berenbaum M., Zangerl A. R., Engeseth N. J. (2000) Honeys from different floral sources as inhibitors of enzymatic browning in fruit and vegetable homogenates. Journal of Agricultural and Food Chemistry 48: 4997-5000.

Ferreira I. C. F. R, Aires E., Barreira J. C. M., Estevinho L. M. (2009) Antioxidant activity of Portuguese honey samples: Different contributions of the entire honey and phenolic extract. Food Chemistry 1 14: 1438-1443.

Kaškoniene V., Maruška A., Kornyšova O., Charczun N., Ligor M., Buszewski B. (2009) Quantitative and qualitative determination of phenolic compounds in honey. Chemical Technology 52(3): 74-80.

Khalil I., Moniruzzaman M., Boukraâ L., Benhanifia M., Islam A., Islam N., Sulaiman S. A., Hua Gan S. (2012) Physicochemical and antioxidant properties of Algerian honey. Molecules 17(9): $11199-11215$.

Krpan M., Marcović K., Šarić G., Skoko B., Hruškar M., Vahčić N. (2009) Antioxidant activities and total phenolics of Acacia honey. Czech Journal of Food Sciences 27: 245-247.
Lanfranco G. (2001) Medicina popolari ta l-imgћoddi filgżejjer Maltin. Klabb Kotba Maltin, Valletta. 261 pp.

Meda A., Lamien C. E., Romito M., Millogo J., Nacoulma O. G. (2005) Determination of the total phenolic, flavonoid and proline contents in Burkina Fasan honey, as well as their radical scavenging activity. Food Chemistry 91(3): 571-577.

Mohamed T. K., Issoufou A., Zhou H. (2012) Antioxidant activity of fractionated foxtail millet protein hydrolysate. International Food Research Journal 19(1): 207-213.

Moien S., Farzami B., Khaghani S., Moein M. R., Larijani B. (2007) Antioxidant properties and protective effect on cell cytotoxicity of Salvia mirzayani. Pharmaceutical Biology 45: 1-6.

Moein S., Reza Moein M. (2010) Relationship between antioxidant properties and phenolics in Zhumeria majdae. Journal of Medicinal Plant Research 4(7): 517-521.

Mundo M. A., Padilla-Zakour O. I., Worobo R. W. (2004) Growth inhibition of foodborne pathogens and food spoilage organisms by select raw honeys. International Journal of Food Microbiology 97: 1-8.

Nagai T., Inoue R., Kanamori N., Suzuki N., Nagashima T. (2006) Characterization of honey from different floral sources. Its functional properties and effects of honey species on storage of meat. Food Chemistry 97: 256262.

National Honey Board (2002) Honey-Health and Therapeutic Qualities. The National Honey Board. Longmont. 258 pp. Available at: http://www.biologiq.n//UserFiles/ Compendium\%2OHoney\%202002.pdf

Oyaizu M. (1986) Studies on products of browning reactions: Antioxidative activities of products of browning reaction prepared from glucosamine. Japanese Journal of Nutrition 44: 307-315.

Persano Oddo L., Piro. R. (2004) Main European unifloral honeys: descriptive sheets. Apidologie 35 (1): 538-581.

Piljac-Žegarac J., Stipčević T., Belščak A. (2009) Antioxidant properties and phenolic content of different floral origin honeys. Journal of ApiProduct and ApiMedical Science 1(2): 43-50.

Sangsrichan S., Wanson W. (2008) The antioxidant capacity of honey samples collected in the north part of 
Thailand in relationship with its total polyphenol. KMITL Science and Technology Journal 8: 1-6.

Savatović S. M., Dimitrijević D. J., Dilas S. M., ČanadanovićBrunet J. M., Ćetković G. S., Tumbas V. T., Štajner D. I. (2011) Antioxidant activity of three different Serbian floral honeys. Acta Periodica Technologica 4242: 145155.

Sheppard W. S., Arias M. C., Grech A., Meixner M. D. (1997) Apis mellifera ruttneri, a new honey bee subspecies from Malta. Apidologie 28: 287-293.
Tungjai M., Poompimon W., Loetchutinat C., Kothan S., Dechsupa N., Mankhetkorn, S. (2008) Spectrophotometric Characterization of Behavior and the Predominant Species of Flavonoids in Physiological buffer: Determination of solubility, lipophilicity and anticancer efficacy. The Open Drug Delivery Journal 2: 10-19. 